\section{Preexposure and locale: A comment}

JAMES L. PATE, Georgia State University, Atlanta, Ga. 30303

Lester (1968) has reported a failure to replicate the preexposure effect found by Pate \& Anders (1967) and has criticized the analytic procedures employed by us. This paper will argue that Lester's reanalysis does not accomplish its objective of correcting for position preferences; in fact, the analysis proposed by Lester deals with a somewhat different experimental question than does the analysis reported by Pate \& Anders (1967). Additionally, it will be shown that Lester's study contains a methodological error similar to the error in a study by Walker, Dember, Earl, Fliege, \& Karoly (1965), which the Pate \& Anders (1967) study was designed to eliminate or reduce.

At the beginning it should be noted that Lester has misread the data in Table 1 of Pate \& Anders (1967). In that table, the number of animals that chose the nonexposed brightness was reported. Of the 30 animals exposed to black, 13 chose the nonexposed or white arm; Lester, however, stated that 17 of the black-exposed animals chose white. It is possible that this is a typographical error, since the chi-square value of 3.89 reported by Lester is correct for the actual data-of 30 white-exposed animals, 25 chose black, while only 17 of the 30 black-exposed animals chose black.

In the Pate \& Anders (1967) report, it was stated that the alternation rate for all animals was significantly different from a chance level as indicated by either a normal curve approximation of the binomial $(z=2.07, p=0.38)$ or by a chi-square analysis of the data as shown at the top of Table $1\left(\chi^{2}=4.26, \mathrm{df}=1, \mathrm{p}<.05\right)$. Lester (1968) stated that although we did not correct for position preference, sufficient data were reported to allow a reanalysis to correct for position preference. His reported chi-square value was obtained from the data as shown in Part A of Table 1; the value is corrected for continuity. (The value is 5.07 without the correction for continuity, which is unnecessary for these data.) This reanalysis indicates that the choice behavior of the rats was related significantly to the preexposure brightness. This is a different experimental question than the one we attempted to answer in Pate \& Anders (1967), but, in general, the conclusions will be similar, i.e., when the alternation rate is significantly above a chance level, choice behavior will be related significantly to preexposure. The chi-square value for the data arranged as at the top of Table 1 will be slightly smaller than the chi-square value for the same data arranged as in Part $A$ of Table 1, if both values are corrected for continuity or if both values are not corrected for continuity.

In Part B of Table 1, a third way of arranging the same data is shown. In this case, the experimental question is whether or not alternation is related to preexposure brightness. For the data reported by Pate $\&$ Anders (1967), alternation was related significantly to preexposure brightness $\left(\chi^{2}=10.33, \mathrm{df}=1, \mathrm{p}<.001\right)$. In the earlier report, it was noted that "animals exposed to white chose the non-exposed brightness significantly more often than did black exposed animals $(z=3.22$, $\mathrm{p}=.0012$ ) [p. 302]." For some data, this arrangement will result in a significant value of chi square, while neither of the other two arrangements will yield significance. The obverse is true also, i.e., the first two arrangements will yield significance but when the data are arranged as in Part B, a nonsignificant chi-square value will be obtained. It should be clear in each of the three analyses that no correction for position or brightness preference has been made or could be made.

One final aspect of Lester's reanalysis requires comment. He stated that, "Detailed analyses indicate that only males show an effect from preexposure [1968, p. 3]." The implication of this statement following immediately his reanalysis is that his detailed analysis showed that only males exhibited the preexposure effect. In the Pate \& Anders (1967) article, the sex difference was discussed and the choice behavior of males and females was compared. It was stated there that only the males showed a significant effect but that the difference between the alternation rates for males and for females was not significant.

Table 1

Arrangements of the Same Alternation Data Alternation, 38; Repetition, 22

\begin{tabular}{lccc}
\hline & & \multicolumn{2}{c}{$\begin{array}{c}\text { Part A } \\
\text { Choice }\end{array}$} \\
\cline { 2 - 4 } & & Black & White \\
\hline Exposure & Black & 17 & 13 \\
Brightness & White & 25 & 5 \\
\hline & & & \multicolumn{2}{c}{ Part B } \\
\cline { 3 - 4 } & & Alter- & Repeti- \\
& & nation & tion \\
\hline Exposure & Black & 13 & 17 \\
Brightness & White & 25 & 5 \\
\hline
\end{tabular}

As for the data reported by Lester (1968), it is clear that his analysis does not correct for position, or more correctly, for position-brightness preference since the analysis is identical to the reanalysis discussed above. However, Lester did obtain data that could have been used to correct for position-brightness preferences. On Day 15, animals were given a single trial in a black-white $T$ maze without preexposure, and 40 of $57(70.2 \%)$ chose black. This percentage could have been used to compute expected frequencies in the chi-square analysis and thus to correct for position-brightness preferences. For example, if preexposure has no effect on subsequent choices, then the percent of animals making a black choice following black exposure should equal the percent of animals making a black choice after white exposure, which would equal the percent of animals making a black choice with no preexposure. When 30 animals are exposed to black, it would be expected that 21 (70\%) animals would select black if exposure had no effect. Analyzing Lester's (1968) data for Day 17 in this way yields a nonsignificant result $\left(\chi^{2}=1.43, \mathrm{df}=1\right.$, $p>.05)$. For Day 24, the data are significant $\left(\chi^{2}=10.31, \mathrm{df}=1, \mathrm{p}<.01\right)$. For Day 33 , the data are again significant $\left(\chi^{2}=5.42\right.$, $\left.\mathrm{df}=1, \mathrm{p}<.05\right)$. Thus Lester has demonstrated a remarkably strong preexposure effect rather than no preexposure effect. It is important to state that the analysis I have reported is based on the assumption that the nonexposed-choice behavior would be stable across days and thus can be used as a base against which to compare data on exposure days.

As has been indicated, the arrangement of the data can affect the outcome of the statistical analysis when the marginal totals are used to compute the expected frequencies. However, in the analysis just reported, the arrangement of the data does not affect the outcome and consequently, whenever the choice behavior is related significantly to preexposure, the alternation behavior will be also. Further, it is possible for the analysis to yield significance even though the overall rate or alternation does not differ from chance. For Days 17, 24, and 33, the frequency of choosing the nonexposed brightness does not differ from chance if it is assumed that the two brightnesses are equally preferred. Also it should be noted that, as Lester (1968) reported, choice behavior is not affected significantly on any day by the preexposure brightness when marginal totals are used to determine the expected frequencies. Only for Day 17 is the alternation rate significantly related to preexposure brightness $\left(\chi^{2}=4.31, \mathrm{df}=1\right.$, 
$\mathrm{p}<.05$ ). For all 3 days, the percent of animals that chose black following white exposure was lower than the percent of animals that chose black with no preexposure. Thus white exposure leads to an increased preference for white rather than to a decreased preference. If it is assumed that the rats tend to avoid white initially because of its fear-provoking characteristics, then exposure allows for the dissipation of the fear and thus an increased tendency to choose white.

Lester's (1968) reanalysis and experiments indicate some of the difficulties in studying choice behavior in a one-trial situation. For the two-trial case, formulas exist for correcting expectancies in terms of position or stimulus preferences, but for the single-trial experiment, equivalent formulas do not exist. Clearly position preferences or brightness preferences may affect the outcome of a preexposure study. Consider the data reported by Lester (1968) in which 40 of 57 animals on a nonexposed day chose black. If this choice frequency is indicative of a persisting organismic tendency, then simple randomization may not be an adequate control. If black-preferring animals are assigned to the black-exposure group, then any preexposure effect would be less likely to be exhibited, since the relatively brief exposure period would have to overcome an organismic tendency. One possible solution to this problem is to use each animal as its own control and expose every animal to all experimental treatments.

A methodological difficulty prevents comparison of the Lester (1968) study and the Pate \& Anders (1967) study. We noted the possibility that stimulation intervening between the exposure and the choice could be important, and a major goal of our study was the elimination or control of extraneous stimulation during the interval between exposure and choice. This control was accomplished by using the exposure box as the startbox of the $\mathrm{T}$ maze. Lester (1968) stated that the only difference between his Study 2 and our experiment was that he transferred his rats from the exposure box to the maze while we only opened a door-this may well be a critical difference rather than a trivial one. In concluding that preexposure in a different locale has no effect, Lester cites another of my studies (Pate, 1967) and indicates that I failed to replicate my own results. In fact, the study cited (Pate, 1967) was an attempt to extend my earlier findings rather than an attempt to replicate the Pate \& Anders (1967) study. In that study (Pate, 1967), it was shown that even when preexposure has no effect on subsequent choices, latency may be affected. In conclusion, it remains an empirical question as to whether or not preexposure in one locale affects later choice behavior in some other locale.

\section{REFERENCES}

LESTER, D. Pre-exposure and stimulus choice: Effects of locale. Psychonomic Science, 1968, $12,3-4$.

PATE, J. L. Choice behavior as a function of stimulus exposure. Psychological Reports, 1967, 21, 213-219.

PATE, J. L., \& ANDERS, T. R. Extra-maze pre-exposure and choice behavior. Psychonomic Science, 1967, 7, 301-302.

WALKER, E. L., DEMBER, W. N., EARL, R. W., FLIEGE, S. E., \& KAROLY, K. J. Choice alternation: II. Exposure to stimulus and stimulus and place without choice. Journal of Comparative \& Physiological Psychology, $1955,48,24-28$.

\section{Reply to Pate}

DAVID LESTER, Suicide Prevention and Crisis Service, 560 Main Street, Buffalo, N.Y. 14202

Several comments are appropriate with regard to Pate's (1970) comments on my study (Lester, 1968).

Pate makes a distinction between several questions: Does preexposure result in alternation, is choice behavior related to preexposure brightness, and is the rate of alternation related to preexposure brightness?

The first and third questions cannot be answered accurately if position and brightness preferences are not taken into account. These preferences affect the chance-expected amount of alternation in the experiment. Pate \& Anders (1967) used a chance-expected amount of alternation of $50 \%$, since they were not able, using their experimental design, to estimate position and brightness preferences. ${ }^{1}$

Since these two questions cannot be answered accurately, I chose to investigate the second of the three questions.

Pate's use of the data from Day 15 of the first study reported in my paper to compute a brightness preference was not utilized by me for the very reason that he gives. We have no evidence that the brightness preference of rats is stable during an experiment. It would seem likely that it may change as a result of their experiences with the stimuli during the experiment. Thus, Pate's computations based on the data from Day 15 of my study seem methodologically unsound.

It is true that my study does not correct for brightness preferences. However, that does not matter, for I am asking a question that does not require me to do so.

With regard to my reporting of Pate and Anders's data, there was a typographical error in my paper.

According to Guilford (1965), a correction for continuity is made in the chi-square test because data in 2 by 2 contingency tables is discrete, whereas the chi-square distribution gives values for a continuous scale. Thus, it seems to me that the correction for continuity is always appropriate.

In conclusion, it appears to me preferable to ask a question that can be answered accurately than one that cannot, given the limitations of experimental design. Further, Pate gives no reason why I should not conclude from my studies that preexposure failed to affect subsequent stimulus choice. My conclusion must stand.

\section{REFERENCES}

GUILFORD, J. P. Fundamental statistics in psychology and education. New York: McGraw-Hill, 1965.

LESTER, D. Pre-exposure and stimulus: Effects of locale. Psychonomic Science, 1968, 12, 3-4.

PATE, J. L., \& ANDERS, T. R. Extra-maze pre-exposure and choice behavior. Psychonomic Science, 1967, 7, 301-302.

PATE, J. L. Pre-exposure and locale: A reply. Psychonomic Science, 1970, 00, 000-000. NOTE

1. The effect of position preferences in two-trial spontaneous alternation is to reduce the chance expectation of alternation to below $50 \%$. Thus, the use of $50 \%$ as the chance-expected amount of alternation is to be conservative. The effect of brightness preferences in the study of preexposure effects may be similar. A944C 